\title{
The Impact of Convective Fluid Inertia Forces on Operation of Tilting-Pad Journal Bearings
}

\author{
Thomas Hagemann, Christopher Zeh, Maximilian Prölß, and Hubert Schwarze
}

Institute of Tribology and Energy Conversion Machinery, Clausthal University of Technology, Leibnizstraße 32, 38678 Clausthal-Zellerfeld, Germany

Correspondence should be addressed to Thomas Hagemann; hagemann@itr.tu-clausthal.de

Received 20 March 2017; Accepted 23 May 2017; Published 11 July 2017

Academic Editor: Fadi Dohnal

Copyright (C) 2017 Thomas Hagemann et al. This is an open access article distributed under the Creative Commons Attribution License, which permits unrestricted use, distribution, and reproduction in any medium, provided the original work is properly cited.

\begin{abstract}
This paper presents a combination of experimental data, CFD analyses, and bearing code predictions on emergence of convective inertia fluid forces within the lube oil flow of tilting-pad journal bearings. Concordantly, experimental data and CFD analyses show a significant rise of local pressure at the transition between inlet and leading edge of tilting-pad, especially for high-speed applications with surface speeds up to $100 \mathrm{~m} / \mathrm{s}$. This effect can be related to convective inertia forces within fluid flow as cross-sections and flow character rapidly change at the pad entrance. An energy-based approach is implemented in the bearing code in order to provide enhanced boundary conditions for Reynolds equation considering this effect. As a result, predictions of bearing code achieved significant improved correlation with measured pressure distributions and CFD-data. Further, beside the local influence, a nonnegligible impact on characteristic parameters of bearing operation such as maximum temperature and stiffness and damping coefficients is observed. Finally, the results are critically analyzed and requirements to gain more distinct and reliable data are specified.
\end{abstract}

\section{Introduction}

The theoretical analysis of the operating characteristic of journal bearings commonly focuses on modelling fluid flow within the lubricant gap by using Reynolds equation. Here, fluid inertia forces are negligible for many practical applications as viscous forces are much higher than inertia ones. However, Reynolds equation is not valid within the whole bearing. For example, within lubricant pockets, boundary layer flow occurs [1-3] and faces combined Poiseuille and Couette flow on the leading edge of the downstream pad [3]. The significant local changes of flow cross-section and flow character potentially generate convective inertia forces as local fluid velocity gradients exist. Nevertheless, most analyses neglect this effect, though it should be of importance especially for tilting-pad bearings due to their tilting degree of freedom and comparably low angular pad span.

This paper presents experimental evidence and theoretical investigations on inertia effects occurring in transition region between pad surfaces and inlet area and concentrates on their influence on local pressure distribution. Further, the impact on selected characteristic parameters of bearing operation is studied.

\section{Materials and Methods}

2.1. Bearing Code Model. The theoretical bearing model is based on a two-dimensional (2D) extended and generalized Reynolds equation and a full three-dimensional (3D) energy equation for bearing, oil film, and journal. Due to the high rotor speed, the temperature distributions in the journal are assumed to be $2 \mathrm{D}$ as the temperature does not vary in circumferential direction. The foundation of the entire bearing model used for the upcoming analyses is comprehensively described in [4-6]. Therefore, the consecutive explanations are reduced due to their relevance for the particular investigations performed here. 
Within the lubricant film following extended and generalized Reynolds equation is applied at stationary operation:

$$
\begin{gathered}
\frac{\partial}{\partial x}\left(\frac{\rho F_{2}}{K_{x}} \frac{\partial p}{\partial x}\right)+\frac{\partial}{\partial z}\left(\frac{\rho F_{2}}{K_{z}} \frac{\partial p}{\partial z}\right) \\
=U \frac{\partial}{\partial x}\left[\rho\left(h-\frac{F_{1}}{F_{0}}\right)\right] .
\end{gathered}
$$

Equation (1) considers the $3 \mathrm{D}$ viscosity distribution due to variable temperature in all three space directions of the fluid film by the following factors [7]:

$$
\begin{aligned}
& F_{0}=\int_{0}^{h} \frac{d y}{\eta}, \\
& F_{1}=\int_{0}^{h} \frac{y}{\eta} d y, \\
& F_{2}=\int_{0}^{h} \frac{y}{\eta}\left(y-\frac{F_{1}}{F_{0}}\right) d y .
\end{aligned}
$$

Additionally, the effects of local turbulent flow or Taylor vortices are included using the coefficients $K_{x}$ and $K_{z}$ [3]. Constantinescu and Galetuse provide an appropriate model to consider inertia effects in Reynolds equation [8]. It assumes that the shape of flow profiles and, therefore, wall shear stresses remain unchanged and do not alter by inertia forces. Consequently, (2) can be extended by inertia terms according to $[8]$

$$
\begin{aligned}
\frac{\partial}{\partial x}\left(\frac{\rho F_{2}}{K_{x}} \frac{\partial p}{\partial x}\right)+\frac{\partial}{\partial z}\left(\frac{\rho F_{2}}{K_{z}} \frac{\partial p}{\partial z}\right) & \frac{\partial}{\partial x}\left(\rho U\left(h-\frac{F_{1}}{F_{0}}\right)\right) \\
& -\frac{\partial}{\partial x}\left(\frac{\rho F_{2}}{K_{x} h}\left(\frac{\partial I_{x x}}{\partial x}+\frac{\partial I_{x z}}{\partial z}\right)\right) \\
& -\frac{\partial}{\partial z}\left(\frac{\rho F_{2}}{K_{z} h}\left(\frac{\partial I_{x z}}{\partial x}+\frac{\partial I_{z z}}{\partial z}\right)\right) .
\end{aligned}
$$

Herein, the integrals of inertia forces are

$$
\begin{aligned}
& I_{x x}=\int_{0}^{h} u^{2} d y=\alpha_{1} U_{m}^{2} h-\alpha_{2} U_{m} U h+\alpha_{3} U^{2} h, \\
& I_{x z}=\int_{0}^{h} u w d y=\alpha_{1} U_{m} W_{m} h-\frac{\alpha_{2}}{2} W_{m} U h, \\
& I_{z z}=\int_{0}^{h} w^{2} d y=\alpha_{1} W_{m}^{2} h .
\end{aligned}
$$

The parameters $\alpha_{1}, \alpha_{2}$, and $\alpha_{3}$ are specific for the flow regime [8]. In addition to laminar and turbulent flow, the bearing model considers the transition range between laminar and turbulent flow, where Taylor vortices appear and no complete turbulent flow is present. Here, a linear interpolation between the parameters of laminar and turbulent flow is used for the turbulence model as well as for the inertia forces in order to stabilize the iterative calculation procedure by preventing step phenomena:
Laminar flow $\left(\operatorname{Re}_{\text {eff }} \leq \operatorname{Re}_{\text {cr }}\right)$ is

$$
\begin{aligned}
& \alpha_{1}=\frac{6}{5} \\
& \alpha_{2}=\frac{1}{5} \\
& \alpha_{3}=\frac{2}{15} .
\end{aligned}
$$

Transition $\left(\operatorname{Re}_{\mathrm{cr}}<\mathrm{Re}_{\mathrm{eff}} \leq 2 \cdot \mathrm{Re}_{\mathrm{cr}}\right)$ is

$$
\begin{aligned}
\alpha_{1}= & \frac{7}{5}-\frac{1}{5} \cdot \frac{\operatorname{Re}_{\mathrm{eff}}}{\operatorname{Re}_{\mathrm{cr}}}, \\
\alpha_{2}= & \frac{2}{5}-\frac{1}{5} \cdot \frac{\operatorname{Re}_{\mathrm{eff}}}{\operatorname{Re}_{\mathrm{cr}}} \\
\alpha_{3}= & \frac{4}{15}-\frac{0.885}{\left(2 \cdot \mathrm{Re}_{\mathrm{cr}}\right)^{0.367}}-\left(\frac{2}{15}-\frac{0.885}{\left(2 \cdot \mathrm{Re}_{\mathrm{cr}}\right)^{0.367}}\right) \\
& \cdot \frac{\operatorname{Re}_{\mathrm{eff}}}{\operatorname{Re}_{\mathrm{cr}}}
\end{aligned}
$$

Turbulent flow $\left(\operatorname{Re}_{\text {cr }}<\operatorname{Re}_{\text {eff }} \leq 2 \cdot \operatorname{Re}_{\text {cr }}\right)$ is

$$
\begin{aligned}
& \alpha_{1}=1, \\
& \alpha_{2}=0, \\
& \alpha_{3}=\min \left(\frac{0.885}{\operatorname{Re}_{\mathrm{eff}}^{0.367}}, \frac{2}{15}\right) .
\end{aligned}
$$

The modified Reynolds equation (3) is solved using Elrod's algorithm [9] neglecting compressibility of the lubricant.

Assuming a boundary layer character of fluid flow in the inlet region the radial distribution of circumferential velocities can be approximated by third-order polynomial approach based on the local layer thickness. Mittwollen [1] proposes a model to predict local boundary layer thickness using the isoviscous boundary layer theory [10]. It is based on Blasius' solutions of Prandtl's boundary layer equations. The one-percent boundary layer thickness of a lengthwise flow of a plane plate can be determined by [10]

$$
\delta=5 \cdot \sqrt{\frac{\nu \cdot x}{U_{\infty}}} .
$$

Considering the pad trailing edge oil flow as a boundary condition at the beginning of the layer, the local laminar boundary layer thickness can be predicted by $[1,10]$

$$
h_{\delta}=5 \cdot \sqrt{\frac{C_{R}{ }^{2} \cdot \varphi_{\delta} \cdot \eta_{m}^{*}}{\operatorname{Re}^{*}}+\left(\frac{h_{E} \cdot \Theta_{E}}{5}\right)^{2}} .
$$

Here $\varphi_{\delta}$ is the angular span of the layer. The transition between laminar and turbulent flow in the inlet region occurs at a Reynolds number of $\operatorname{Re}_{\delta \text {,eff,cr }}=1511$. Flow transition is a local phenomenon, and, consequently, either the whole inlet 


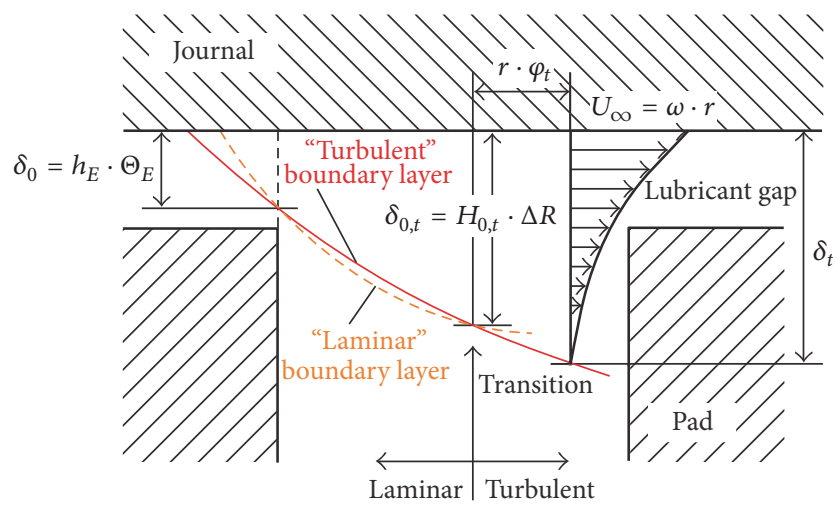

FIGURE 1: Boundary layer in the inlet region at laminar and turbulent flow according to [1].

region or a certain part of it can be turbulent if the criterion $\operatorname{Re}_{\delta \text {,eff,cr }}>1511$ is fulfilled. Thus, the initial thickness of the turbulent boundary layer can be equal to the effective filled gap of the upstream pad or it matches the laminar boundary layer thickness in case of transition within the inlet region. A power ansatz is used to approximate the velocity profile of the turbulent boundary layer. The 1/7-power ansatz using additional empirical data leads to [10]

$$
\delta_{t}=0,37 \cdot x \cdot \mathrm{Re}_{x}^{-1 / 5} .
$$

Here, $\operatorname{Re}_{x}$ is the Reynolds number calculated using the virtual length of the turbulent boundary layer. Introducing the nondimensional thickness $H=h / C_{R}$ provides a consistent expression for the turbulent boundary layer thickness based on all previously mentioned boundary conditions [1]:

$$
\begin{aligned}
& h_{\delta_{t}} \\
& =0,37 \\
& \quad \cdot\left[\frac{\varphi_{t}}{\psi}+\left(\frac{H_{E} \cdot \Theta_{E}}{0,37} \cdot\left(\frac{\mathrm{Re}}{\eta_{m}^{*}}\right)^{1 / 5}\right)^{5 / 4}\right]^{4 / 5}\left(\frac{\mathrm{Re}}{\eta_{m}^{*}}\right)^{-1 / 5} \\
& \quad \cdot C_{R} .
\end{aligned}
$$

Figure 1 presents the basic formation of laminar and turbulent boundary layer. Dissipation in the inlet region can be determined by the wall shear stress according to $[1,10]$.

2.2. Investigated Bearings. Investigations are conducted for two tilting-pad journal bearings. The first one depicted in Figure 2 is a four-pad bearing with an eccentrical rocker-pivot typically applied in smaller turbines or compressors. Oil is supplied via three nozzles between each pad. The clearance between journal and baffle is about 3.5 times the minimum radial clearance of the lubricant gap to provide a nearly unrestricted discharge oil flow. Moreover, the baffles contain several bores in order to reduce the side flow resistance. References [11-13] provide a description of the test rig that the bearing is investigated with.

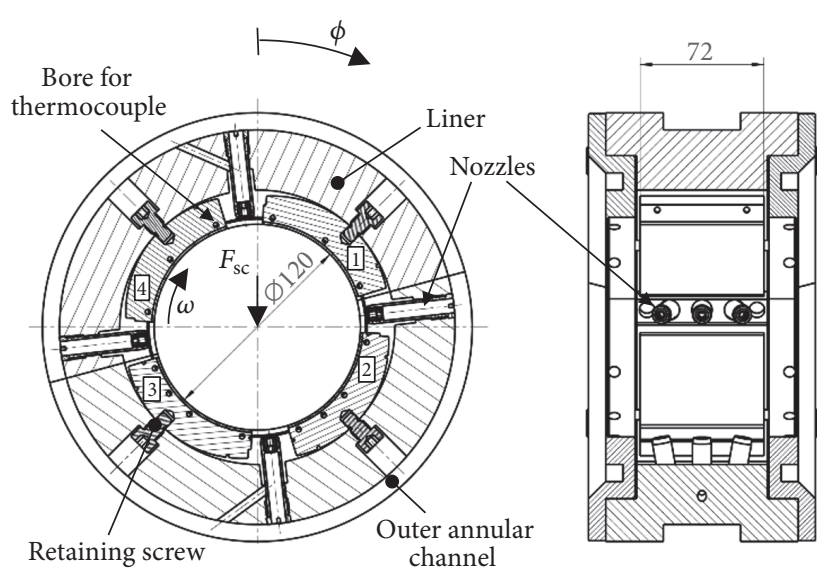

FIGURE 2: Tilting-pad bearing (TPB120).

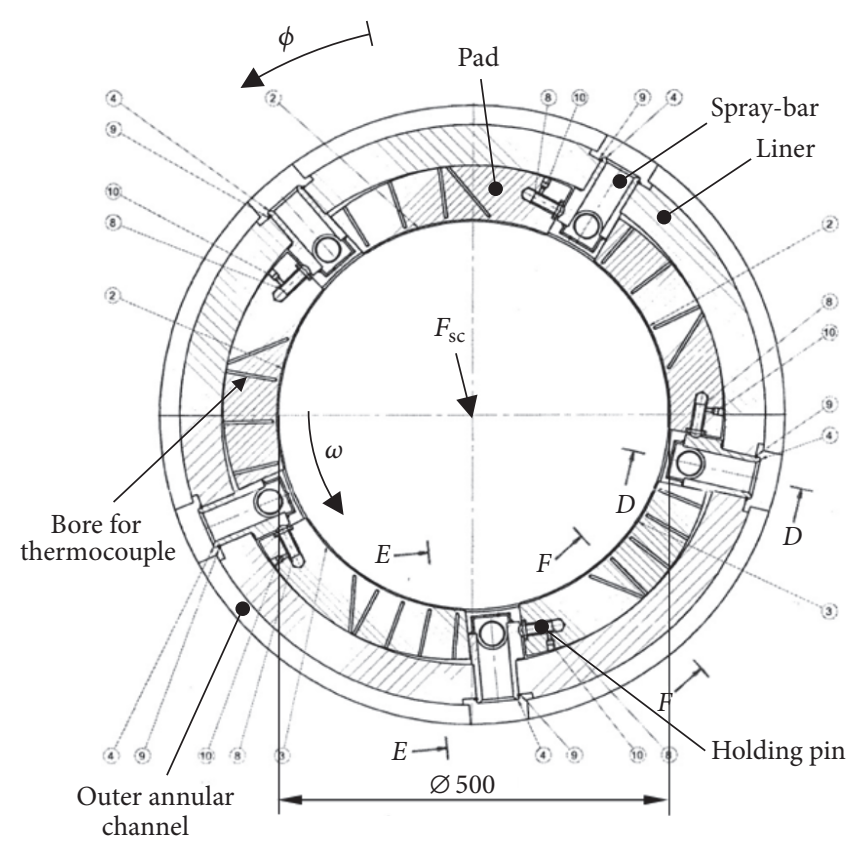

FIGURE 3: Tilting-pad bearing (TPB500).

The second bearing is a flooded lubricated five-pad bearing for large turbine applications already investigated in [4-6] and shown in Figure 3. The bearing features an elliptical contact between pads and liner with a pivot offset of 0.6 . Further, sealing baffles with a radial clearance of $C_{R, \text { baffle }}=$ $1.0 \mathrm{~mm}$ are arranged on both bearing sides.

Figures 2 and 3 include a description of the load situation, the origin of the angular coordinate, and conventions for pad declarations that the subsequent results are related to.

The key parameters of the analysis and the geometry of the bearings are listed in Table 1. Measurement data for the two bearings is provided by previous investigations $[5,6,12]$.

2.3. CFD Analyses. CFD analyses are conducted for TPB120 bearing. The model consists of a three-dimensional fluid and 
TABLE 1: Key parameters of analysis.

\begin{tabular}{|c|c|c|}
\hline \multirow{2}{*}{ Parameter } & \multicolumn{2}{|c|}{ Value } \\
\hline & TPB120 & TPB500 \\
\hline \multicolumn{3}{|c|}{ Geometrical properties } \\
\hline Number of tilting-pads & 4 & 5 \\
\hline Nominal diameter, mm & 120 & 500 \\
\hline Tilting-pad thickness, mm & 20 & 72.5 \\
\hline Bearing width, $\mathrm{mm}$ & 72 & 350 \\
\hline $\begin{array}{l}\text { Angular length of tilting-pads, } \\
\text { degrees }\end{array}$ & 70 & 56 \\
\hline $\begin{array}{l}\text { Relative position of tilting-pad } \\
\text { support }\end{array}$ & 0.6 & 0.6 \\
\hline Radial clearance, $\mu \mathrm{m}$ & 108 & 300 \\
\hline Preload & 0.50 & 0.23 \\
\hline \multicolumn{3}{|c|}{ Static analysis parameters } \\
\hline Bearing load, $\mathrm{kN}$ & $175-438$ & $175-438$ \\
\hline Rotational speed, rpm & $6000-15000$ & $1500-3000$ \\
\hline Lubricant supply temperature, ${ }^{\circ} \mathrm{C}$ & 50 & 50 \\
\hline Lubricant flow rate, $1 / \mathrm{s}$ & 1.5 & 7.0 \\
\hline \multicolumn{3}{|c|}{ Lubricant properties } \\
\hline Lubricant & ISO VG 32 & ISO VG 32 \\
\hline Lubricant density $\mathrm{kg} / \mathrm{m}^{3}$ & $865 @ 40^{\circ} \mathrm{C}$ & $844 @ 40^{\circ} \mathrm{C}$ \\
\hline $\begin{array}{l}\text { Lubricant specific heat capacity } \\
\mathrm{kJ} /(\mathrm{kg} \mathrm{K})\end{array}$ & $2.0 @ 20^{\circ} \mathrm{C}$ & $2.17 @ 70^{\circ} \mathrm{C}$ \\
\hline \multicolumn{3}{|c|}{ Thermal boundaries and material properties } \\
\hline $\begin{array}{l}\text { Lubricant thermal conductivity, } \\
\mathrm{W} /(\mathrm{m} \mathrm{K})\end{array}$ & 0.13 & 0.13 \\
\hline $\begin{array}{l}\text { Pad and journal thermal } \\
\text { conductivity, } \mathrm{W} /(\mathrm{m} \mathrm{K})\end{array}$ & 45 & 45 \\
\hline Pad ambient temperature, ${ }^{\circ} \mathrm{C}$ & 60 & 65 \\
\hline
\end{tabular}

structure part and is implemented in commercial software. The structure part is assumed as rigid, and accordingly, only its influence on heat flow is considered. Thermomechanical deformation and radial pad deflection due to pivot elasticity $s(\phi, z)$ are imported from the bearing code and determined by approximate formulas [4]. The local film thickness of pad number $i$ is described by

$$
\begin{aligned}
& h(\phi, z)_{i}=C_{R} \cdot\left(\frac{1}{1-m_{i}}-\frac{m_{i}}{1-m_{i}} \cdot \cos \left(\phi-\varphi_{F, i}\right)\right. \\
& \left.\quad-\frac{\delta_{i}}{\psi} \cdot\left(1+\psi_{\mathrm{pad}, i}\right) \cdot \sin \left(\phi-\varphi_{F, i}\right)+\varepsilon \cdot \cos (\phi-\beta)\right) \\
& \quad+s(\phi, z) .
\end{aligned}
$$

Herein the preload of the pad $m$ and the relative pad thickness $\psi_{\text {pad }}$ are defined as

$$
\begin{aligned}
m & =1-\frac{C_{R}}{R_{B}-r}, \\
\psi_{\text {pad }} & =\frac{t_{B}}{r} .
\end{aligned}
$$

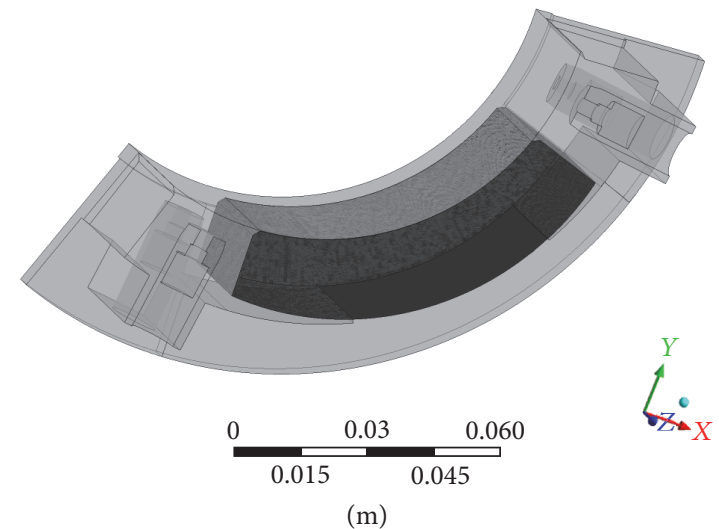

FIGURE 4: Fluid-model (light grey) and structure-model (dark grey) for CFD analyses.

Equation (12) equals the expression applied in the bearing code. Due to limited computational capacities, many investigations are performed with a simplified model consisting of one pad and an upstream and downstream inlet region. This model shown in Figure 4 consists of approximately 1.4 million cells and assumes axial symmetry to the middle plane. At the selected fluid-structure interfaces the grid is refined in order to model heat transfer within the small temperature boundary layer due to high Prandtl numbers reliably. As investigations actually focused also on heat transfer among surfaces directly facing the inlet region in circumferential direction conjugate heat transfer is defined here in addition to the sliding surface. To reduce deviations between models of bearing code and CFD analyses heat transfer coefficients are set on the backside and the lateral boundary surfaces of the pad. Further, geometry of the bearing with its thin lubricant film region and comparably high circumferential and axial length scales provides negative effects for the grid quality that could be measured by comparably high aspect ratios. Therefore, a comprehensive verification procedure is conducted to determine a robust grid resolution. The origin of axial orientated $z$-axis is located on the lateral edge of the pad.

A key objective of CFD-analysis is to investigate special phenomena that are not measurable reliably in order to develop models that are suitable to be integrated into the time efficient bearing code. A major benefit of the CFDmodel approach described above is that the model can easily be adapted to the bearing model by boundary conditions. Hence, deviations between predicted results of CFD analyses and bearing code reduce to a limited number of physical phenomena as several other effects that are present in a complete bearing model are suppressed. These physical phenomena are expected to be captured more precisely by CFD analyses or not included in the bearing code.

The inlet boundary conditions for CFD analyses visible by black arrows in Figure 5 are imported from the bearing code. These include temperature and flow velocity distributions transferred to the CFD grid by interpolation at the trailing edge of the upstream pad as well as in the inlet of the nozzles. 


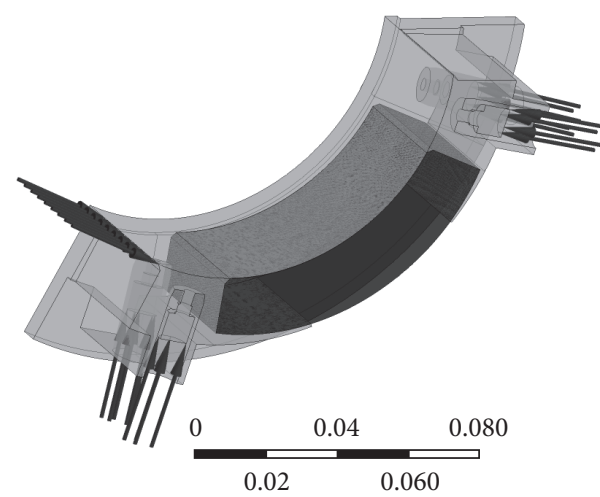

(m)

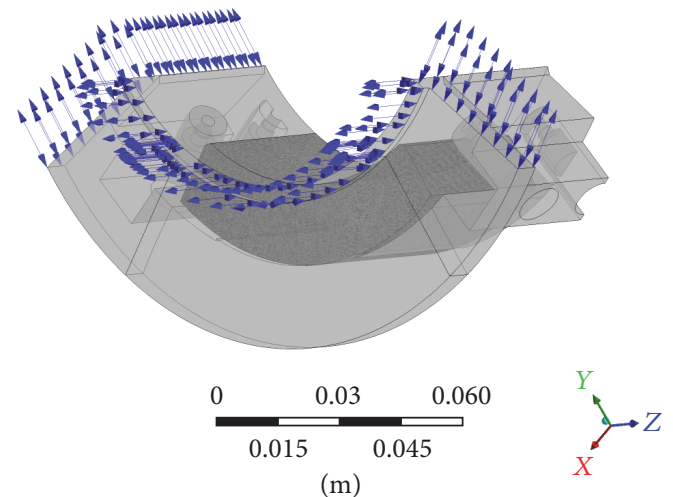

(b)

FIGURE 5: Inlet (a) and outlet (b) boundary conditions for CFD analyses.

At the axial outlet between baffle and journal and the remaining flow cross-sections in circumferential direction opening boundary conditions are defined which are noticeable by blue arrows in Figure 5(b).

The remaining surfaces represent walls with defined heat transfer coefficients. Furthermore, journal speed and temperature match the ones of the bearing code.

\section{Results and Discussion}

In a first step, a verification procedure between bearing code and CFD-analysis is conducted. For this purpose, two approaches are applied. In the first one, all parameters of the local film thickness function (12) are set equal to produce equal film thickness in the pad area in both software packages. Secondary, an iterative procedure is implemented in CFDanalysis modifying journal eccentricity and tilting angle until mechanical equilibrium for the same load on pad as determined by the bearing code is reached. The investigations indicated that the latter one produces better comparable results. The constraints of the former one prove too restrictive and generate different results, though differences concerning tilting angle and eccentricity are comparably small. Figure 6 contains a comparison of central oil film pressure distributions for pad number 3. A significant difference can be observed at the trailing edge of the pad, where CFD analyses show a step-shaped increase of pressure from the level of the inlet region where pressure equals the ambient one.

The interfaces between the inlet region and the pad represent nearly stepwise changes of flow cross-section, which are only reduced by bevels or curvatures applied at the leading and trailing edge of the pad. Therefore, influence of fluid inertia forces at the entrance and exit of the lubricant gap in circumferential direction have to be expected with high probability. According to the previously described model for the fluid flow in the inlet region, boundary layer thickness corresponds with the local film thickness at the trailing edge of the pad. Consequently, velocity gradients are small and concordantly inertia forces are comparably low. This assumption seems reasonable looking at trailing edge conditions in
Figure 7 as thin boundary layer overflows a section of low fluid velocities without significant disturbances. However, at the leading edge of downstream pad significant velocity gradients occur. Therefore, maximum pressure within this region is located in the upper right corner comparable to lid driven cavity flow. Black arrows indicate the mayor flow directions in Figure 7(b).

Beside the complex flow in transition area between pad and inlet boundary layer flow is present in the inlet and combined Poiseuille and Couette flow on the pad as described earlier and illustrated in Figure 8.

A simple approach predicting entrance pressure at the leading edge and appropriate to implement in a bearing code based on Reynolds equation can be derived from the energy theorem first proposed by Pan [14] and comprehensively discussed by Constantinescu [15]. The radial distribution of local circumferential velocity $\boldsymbol{u}_{\mathrm{bl}, \phi}$ within boundary layer is well approximated by a third-order polynomial approach, as local boundary layer thickness is known from (9) or (11). Using the subsequent boundary conditions

$$
\begin{gathered}
u_{\mathrm{bl}, \phi}\left(y^{\prime}=0\right)=U, \\
u_{\mathrm{bl}, \phi}\left(y^{\prime}=\delta\right)=0, \\
\frac{\partial u_{\mathrm{bl}, \phi}}{\partial y^{\prime}}\left(y^{\prime}=\delta\right)=0, \\
\frac{\partial^{2} u_{\mathrm{bl}, \phi}}{\partial y^{2}}\left(y^{\prime}=\delta\right)=0,
\end{gathered}
$$

provides the polynomial coefficients in order to determine local fluid velocity distribution in radial direction:

$$
u_{\mathrm{bl}, \phi}\left(\phi, y^{\prime}, z\right)=U \cdot\left(1-3 \cdot y^{\prime}+3 \cdot y^{\prime 2}-y^{\prime 3}\right) .
$$

Consequently, local mean velocity of the boundary layer facing the lubricant film results from

$$
\bar{u}_{\mathrm{bl}, \phi}(\phi, z)=\frac{1}{h} \cdot \int_{0}^{h} u_{\mathrm{bl}, \phi}\left(\phi, y^{\prime}, z\right) d y^{\prime} .
$$



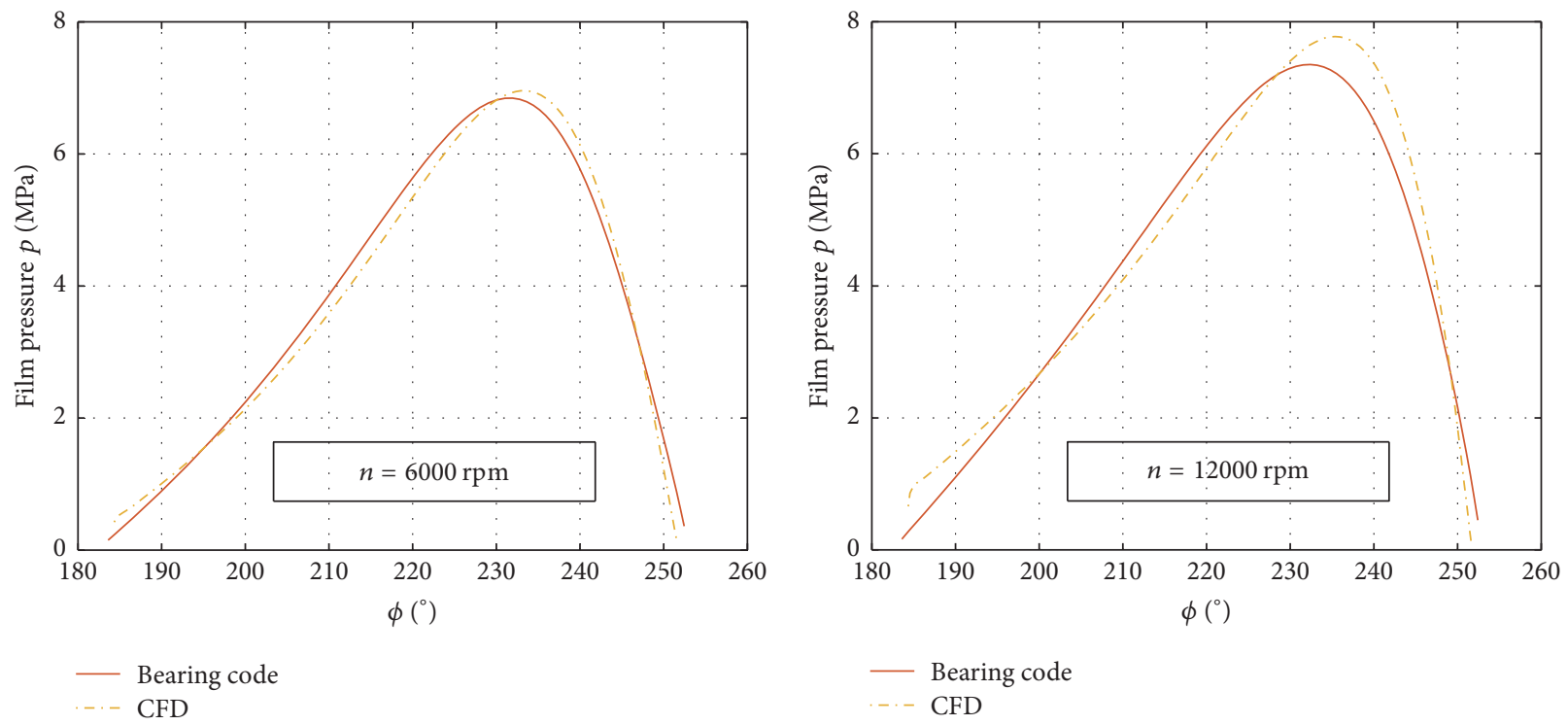

FIGURE 6: Comparison of predicted pressure distributions on pad $3\left(\mathrm{TPB} 120, p_{q}=2.0 \mathrm{MPa}, \mathrm{Q}=90 \mathrm{l} / \mathrm{min}, T_{\text {sup }}=50^{\circ} \mathrm{C}, z=36 \mathrm{~mm}\right)$.

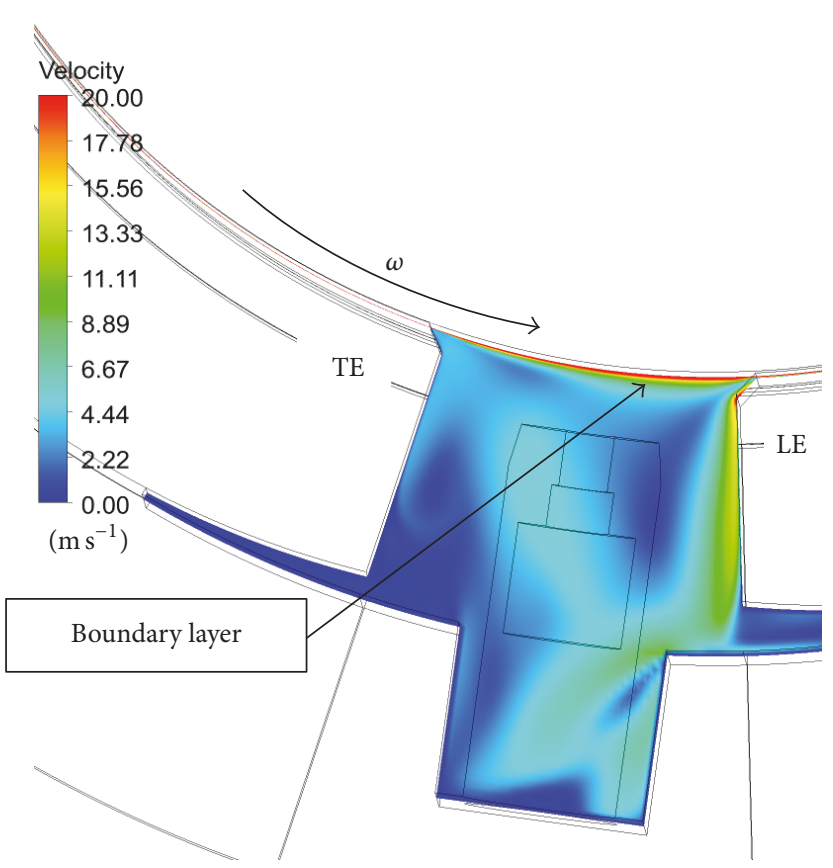

(a)

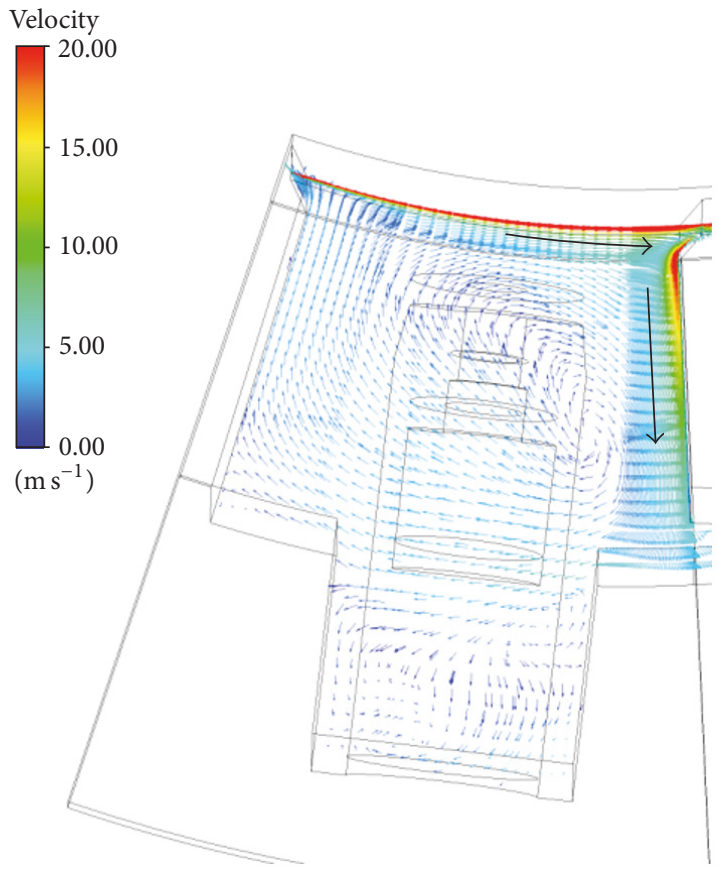

(b)

FIGURE 7: Absolute fluid velocities in the inlet region between pads 2 and $3\left(\mathrm{TPB} 120, n=12000 \mathrm{~min}^{-1}, p_{q}=2,0 \mathrm{MPa}, Q=901 / \mathrm{min}, T_{\text {sup }}=\right.$ $50^{\circ} \mathrm{C}$, and $z=30 \mathrm{~mm}$ ).

Considering the mean velocity at the leading edge of pad region $\bar{u}_{\mathrm{pad}, \mathrm{le}, \phi}$ the pressure increase can be derived from energy approach:

$$
\Delta p(z)=\frac{\rho}{2}\left(\bar{u}_{\mathrm{bl}, \phi}^{2}-\bar{u}_{\mathrm{pad}, \mathrm{le}, \phi}^{2}\right) .
$$

The lower limit of $\bar{u}_{\mathrm{bl}, \phi}$ is $U / 2$ if the boundary layer thickness matches the film thickness. Boundary layer thickness increases with a reduction of speed. Consequently, mean relative velocity in the boundary layer facing the leading edge gap $\bar{u}_{\mathrm{bl}, \phi} / U$ increases. However, rising wall velocity $U$ implies an increasing difference of the quadratic velocities in (17), and therefore, it results in higher values of $\Delta p$. The previously described assumptions neglect that oil which is not transported into the lubricant film meets inertia forces as wall boundary condition provokes a change of the flow direction. 


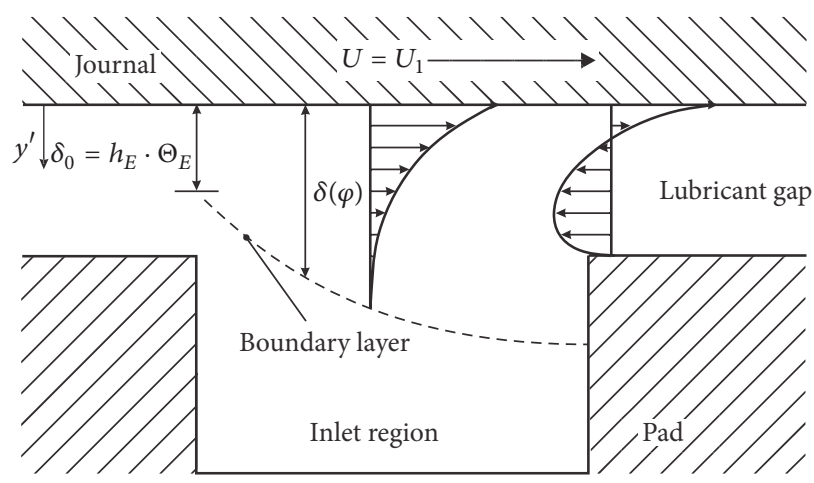

FIGURE 8: Flow profile in inlet and leading edge pad region.

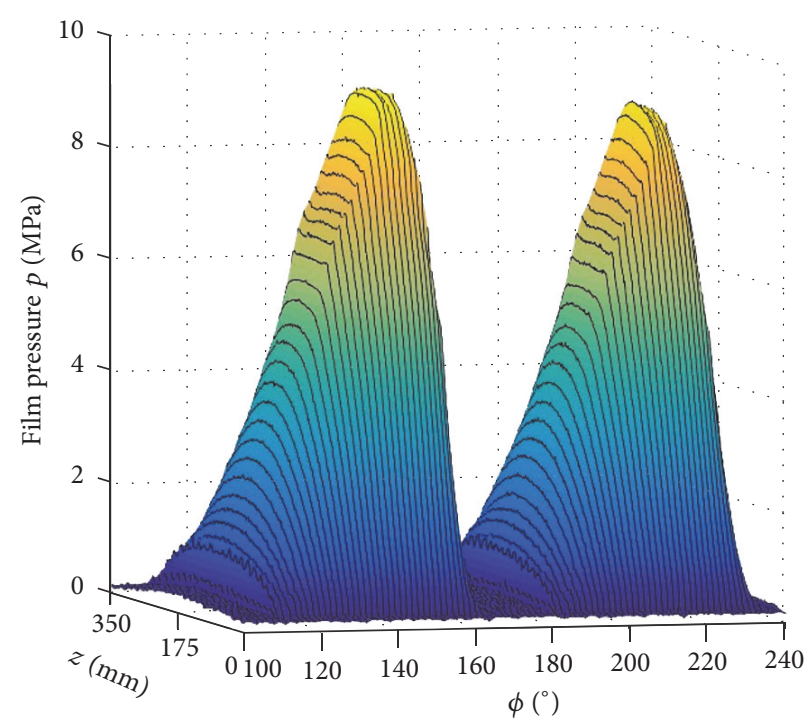

(a)

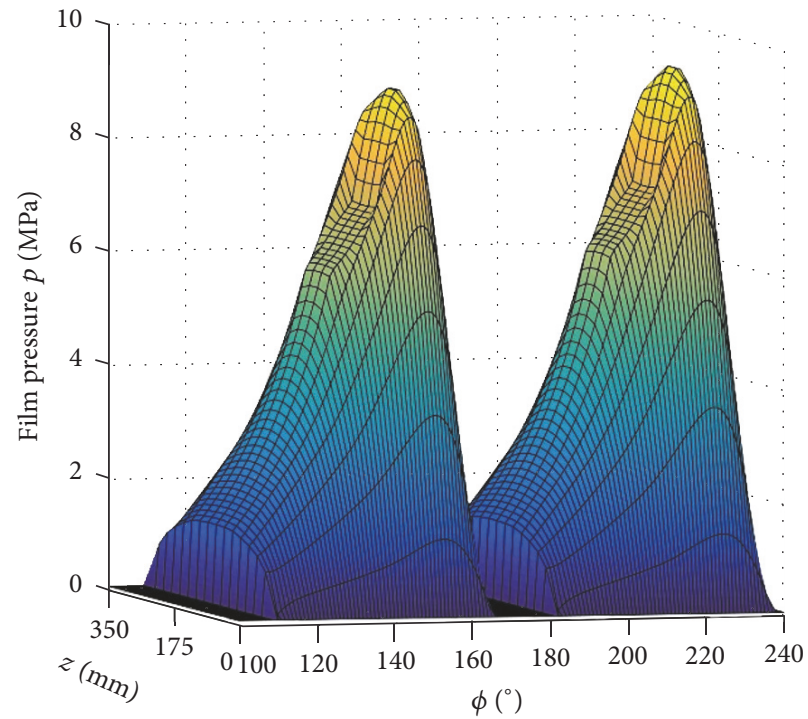

(b)

Figure 9: Measured $[5,6]$ and predicted pressure distribution on the loaded pads 3 and 4 (TPB500, $n=3000 \mathrm{~min}^{-1}, p_{q}=2.0 \mathrm{MPa}, \mathrm{Q}=$ $420 \mathrm{l} / \mathrm{min}$, and $\left.T_{\text {sup }}=50^{\circ} \mathrm{C}\right)$.

This relation tends to increase the pressure difference while the existent lateral flow slightly decreases it. However, the pressure increase is no exact step phenomena, and hence, (17) seems to be a good compromise in order to provide a suitable approach to model this effect. Gauge pressure from (17) is defined as an offset to the pressure in the inlet region located on its last nodes in circumferential direction. This approach is chosen with respect to numerical robustness and not to a certain physical argument. The boundary condition remains unchanged during the iterative procedure to find the mechanical equilibrium of the tilting-pad for a certain journal position and is numerically damped in order to provide robust convergence of the complete calculation.

Experimental evidence for the presence of the pressure rise at the leading edge exists within measurement results for both bearings introduced in Table 1 . The test rig introduced in $[5,6,16]$ is able to measure a pressure and film thickness distribution within the whole film by a lateral movement of the shaft. Two capacitive proximity probes and two piezoelectric pressure sensors are mounted in the shaft rotated $90^{\circ}$ to each other. In circumferential direction the resolution is fixed at 240 values and in axial direction it increases with rising speed up to about 4000 values per angular measurement point. Figure 9 shows a comparison of measured and predicted pressure distribution on the two maximum loaded pads of the TPB500 at a rotor speed of $3000 \mathrm{rpm}$ and a specific load of 2.0 MPa. The pressure increase is clearly observable within measurement data at both pads in Figure 9(a). The lateral resolution accounts for 2400 values. The shape of the pressure rise determined by simulation applying the above-described model matches the experimental results; however, the absolute values are overpredicted. According to Figure 10, this characteristic could be observed within the whole operating range. Consequently, measurement results disagree with the hypothesis that the theoretical model should provide smaller values. 


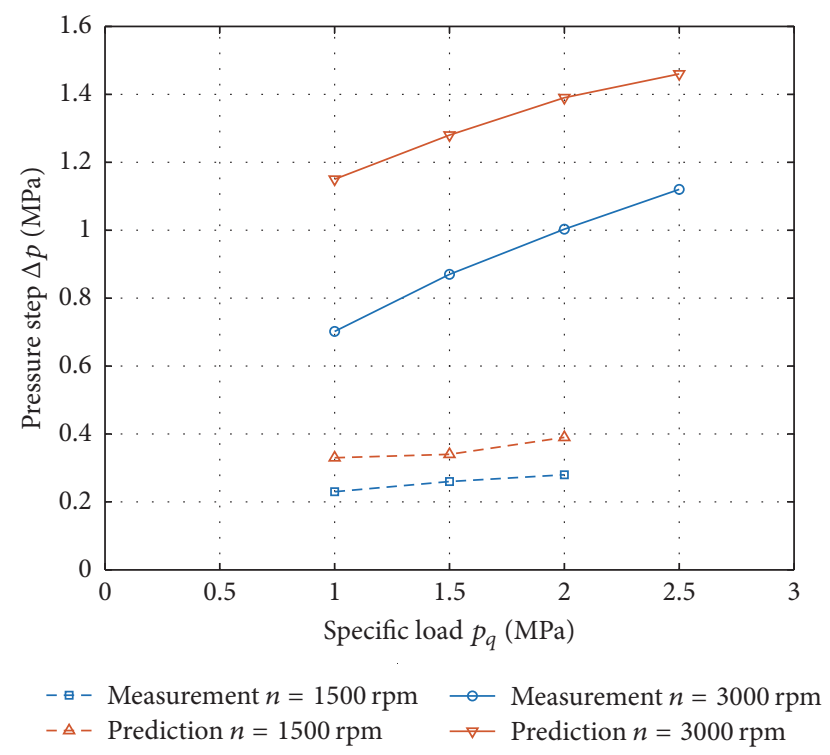

Figure 10: Measured [5, 6] and predicted pressure increase at leading edge of pad 4 (TPB500, $Q=420 \mathrm{l} / \mathrm{min}$, and $\left.T_{\text {sup }}=50^{\circ} \mathrm{C}\right)$.

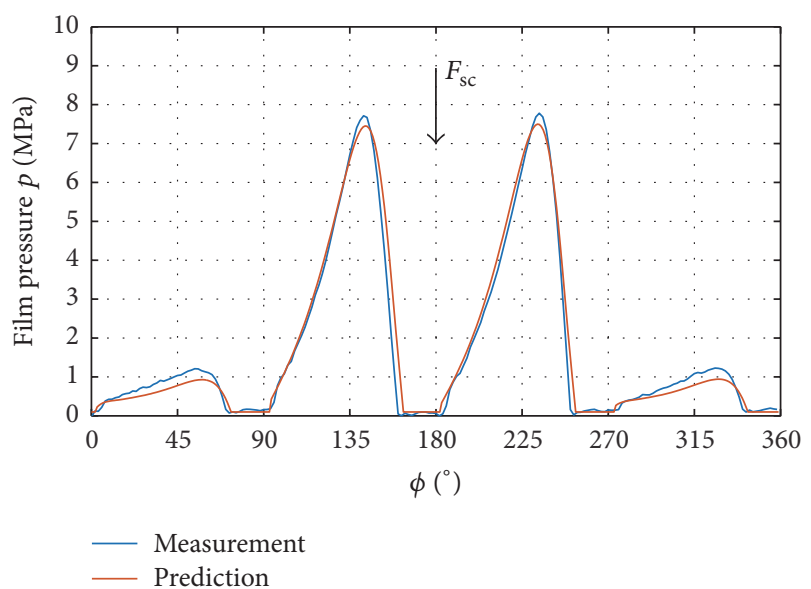

FIGURE 11: Measured and predicted pressure distribution (TPB120, $n=6000 \mathrm{~min}^{-1}, p_{q}=2.0 \mathrm{MPa}, Q=90 \mathrm{l} / \mathrm{min}, T_{\text {sup }}=50^{\circ} \mathrm{C}$, and $z=36 \mathrm{~mm})$.

The TPB120 was investigated experimentally in [12] and theoretically by the bearing code and CFD analyses. Figures 11-13 show a comparison of predictions performed by the bearing code and measurement data for different rotor speeds at constant bearing load. In general, good agreement is reached. Concordantly, inertia effects at leading edge are negligible at $6000 \mathrm{rpm}$, while they are clearly observable at $12000 \mathrm{rpm}$ and $15000 \mathrm{rpm}$. At $15000 \mathrm{rpm}$ a local pressure maximum on the upper pads is predicted shortly behind the leading edge. Measurement data at $12000 \mathrm{rpm}$ and $15000 \mathrm{rpm}$ tends to prove this phenomenon.

Further, the results can be compared to CFD-data in Figure 14. The correlation between CFD-data and bearing code prediction in Figure 14 is good for $6000 \mathrm{rpm}$ and excellent

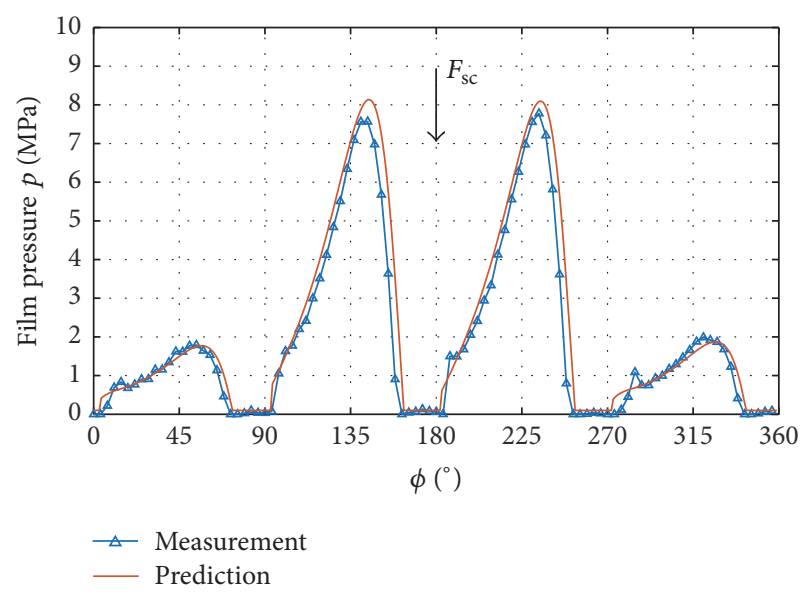

FIGURE 12: Measured and predicted pressure distribution (TPB120, $n=12000 \mathrm{~min}^{-1}, p_{q}=2.0 \mathrm{MPa}, Q=90 \mathrm{l} / \mathrm{min}, T_{\text {sup }}=50^{\circ} \mathrm{C}$, and $z=36 \mathrm{~mm})$.

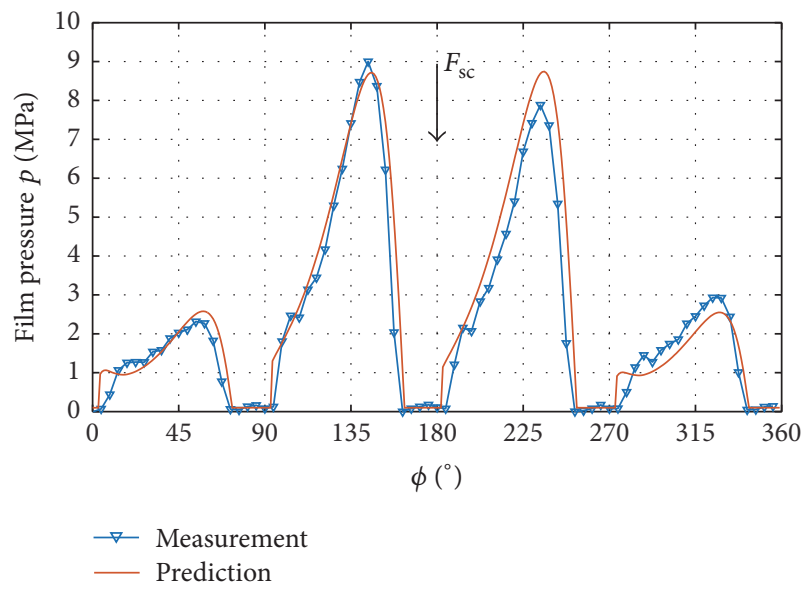

FIGURE 13: Measured and predicted pressure distribution (TPB120, $n=15000 \mathrm{~min}^{-1}, p_{q}=2.0 \mathrm{MPa}, Q=901 / \mathrm{min}, T_{\text {sup }}=50^{\circ} \mathrm{C}$, and $z=36 \mathrm{~mm})$.

for $12000 \mathrm{rpm}$. Results of CFD-simulation for the leading edge pressure step prove to be very robust and insensitive concerning the grid within the inlet region. The comparison between prediction and measurement data in Figures 11-14 shows generally good agreement. The impact of inertia forces at the leading edge of pad is observable distinctly. However, discrepancies can also be detected. The markers in Figures 12 and 13 indicate the limited resolution of the measurement which is reduced with increasing speed as the sampling frequency remains at $40 \mathrm{kHz}$. Hence, at $15000 \mathrm{rpm} 80$ values are detected in circumferential direction and the distance between two points accounts for $\Delta \phi=4.5^{\circ}$. Moreover, the piezoelectric pressure sensors and their adapters mounted in two lateral planes in the journal according to Figure 15 have a diameter of approximately $12 \mathrm{~mm}$ and they are not smoothing completely to the sliding surface of the journal. Consequently, the detected pressure values represent a mean 

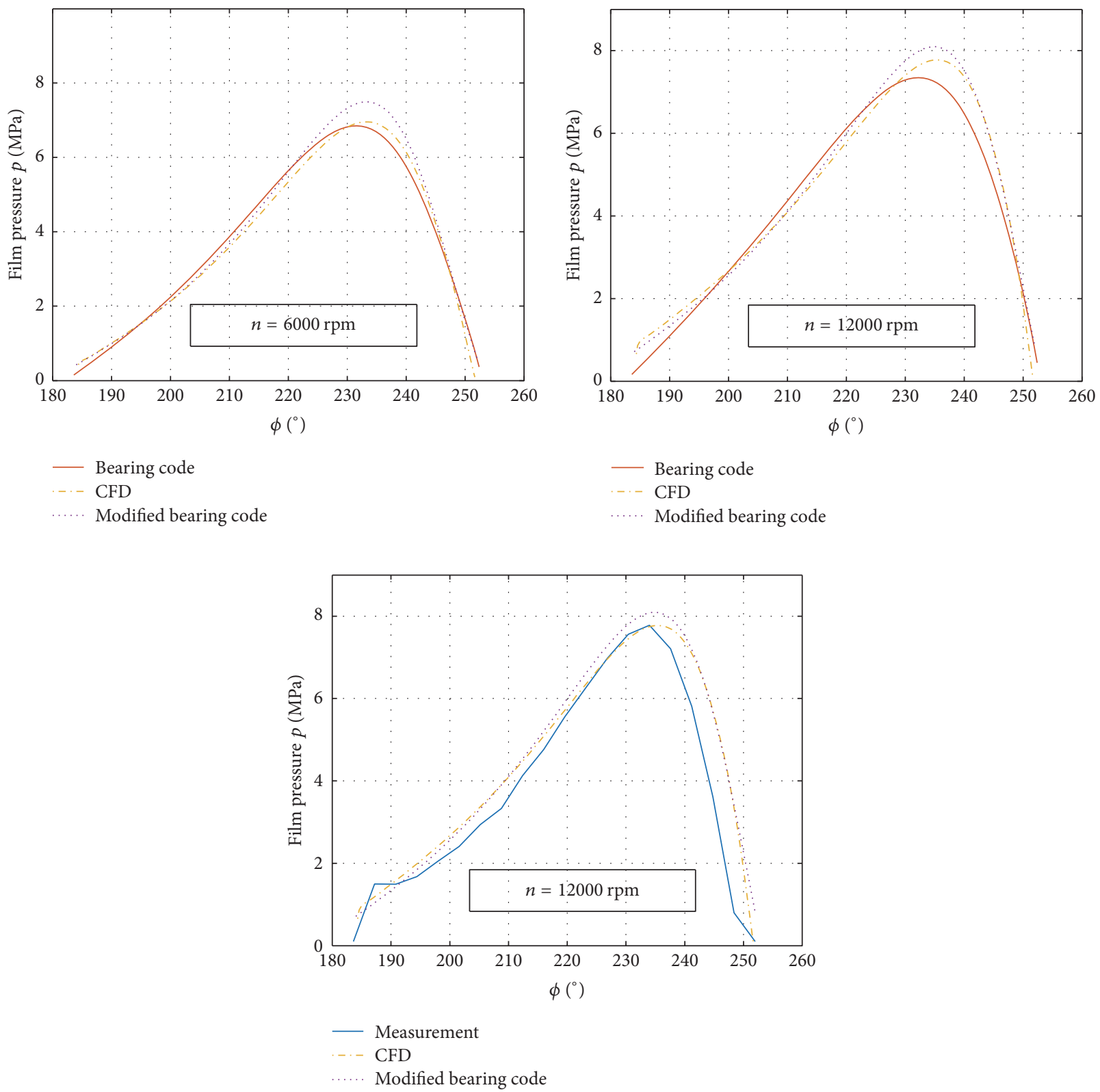

FIGURE 14: Comparison of measured and predicted pressure distributions on pad number 3 considering enhanced boundary conditions (TPB120, $p_{q}=2.0 \mathrm{MPa}, Q=90 \mathrm{l} / \mathrm{min}, T_{\text {sup }}=50^{\circ} \mathrm{C}$, and $z=36 \mathrm{~mm}$ ).

up to $11^{\circ}$. Therefore, high pressure gradients are measured with higher uncertainties.

The subsequently presented results refer to sensitivity of selected characteristic bearing parameters on modelling of convective inertia forces. Here, predictions first neglecting inertia forces, secondly using only the boundary condition from (17), and finally considering the boundary condition from (17) and inertia forces in the lubricant gap are compared. As expected, the maximum sensor temperature depicted in Figure 16 referring to the thermocouple locations shown in Figure 2 is predicted nearly equally for lower speeds.
However, with increasing speed deviations occur and rise up to $\Delta T=5.4 \mathrm{~K}$ at $15000 \mathrm{rpm}$. As a reference, Figure 16 includes measurement results.

The main stiffness coefficients derived from the stationary results by perturbation method and presented in Figure 17 indicate more sensitivity related to modelling than the main damping coefficients in Figure 18. This property might be related to the impact of pressure gradients on stiffness coefficients. Figure 19 includes a comparison of predicted local pressure distributions in order to illustrate local deviations due to modelling which are present on all four pads. 


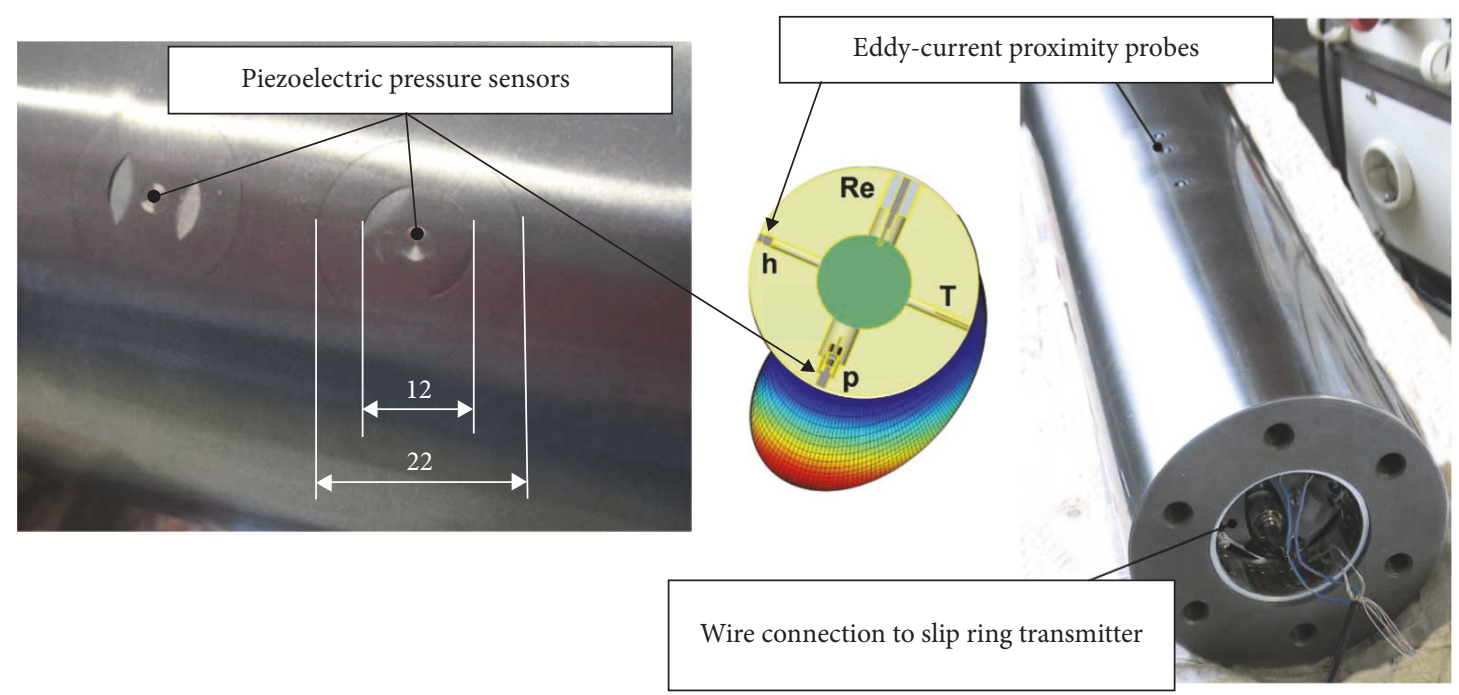

FIGURE 15: Rotor-sided applied sensors [11].

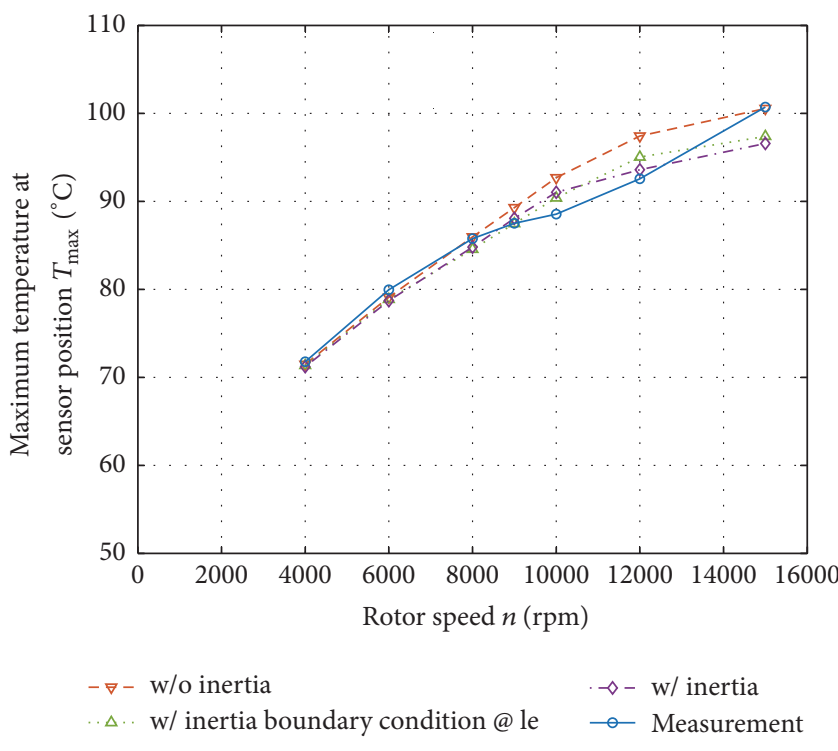

FIGURE 16: Comparison of measured and predicted maximum sensor temperatures for different simulation boundary conditions (TPB120, $p_{q}=2.0 \mathrm{MPa}, Q=90 \mathrm{l} / \mathrm{min}, T_{\text {sup }}=50^{\circ} \mathrm{C}$, and $z=36 \mathrm{~mm}$ ).

\section{Conclusions}

The investigations show the impact of fluid convective inertia forces at the leading edge of tilting-pad journal bearings. Concordantly, measurement data and CFD analyses indicate that the pressure characteristic is significantly influenced by this phenomenon, especially at elevated rotor speeds. A simple energy approach is proposed and implemented in the bearing code to improve the quality of boundary conditions for Reynolds equation. The enhanced bearing model shows good agreement with experimental and CFD-data. Here, results provide evidence that inertia effects within the pad

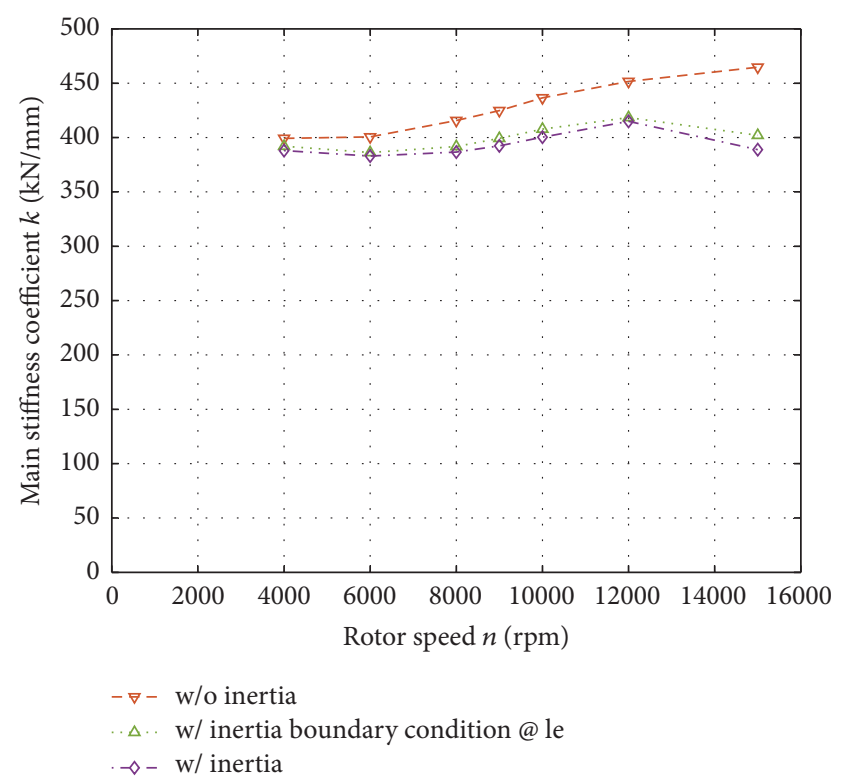

FIGURE 17: Comparison of predicted synchronous main bearing stiffness for different simulation boundary conditions (TPB120, $p_{q}=$ 2.0 MPa, $Q=90 \mathrm{l} / \mathrm{min}, T_{\text {sup }}=50^{\circ} \mathrm{C}, z=36 \mathrm{~mm}$, and $k_{\text {pivot }}=$ $0.8 \mathrm{kN} / \mathrm{mm})$.

area become more important due the impact of leading edge boundary condition.

However, the results presented here were identified within investigations with a different focus. Therefore, the quality of the CFD grid is not sufficient enough to give a detailed answer on the transition of the flow profile at leading edge where it changes from boundary layer to combined Poiseuille and Couette flow. Further, a higher sampling rate and a modified pressure measurement should be aspired for a more detailed resolution of the leading edge pressure 


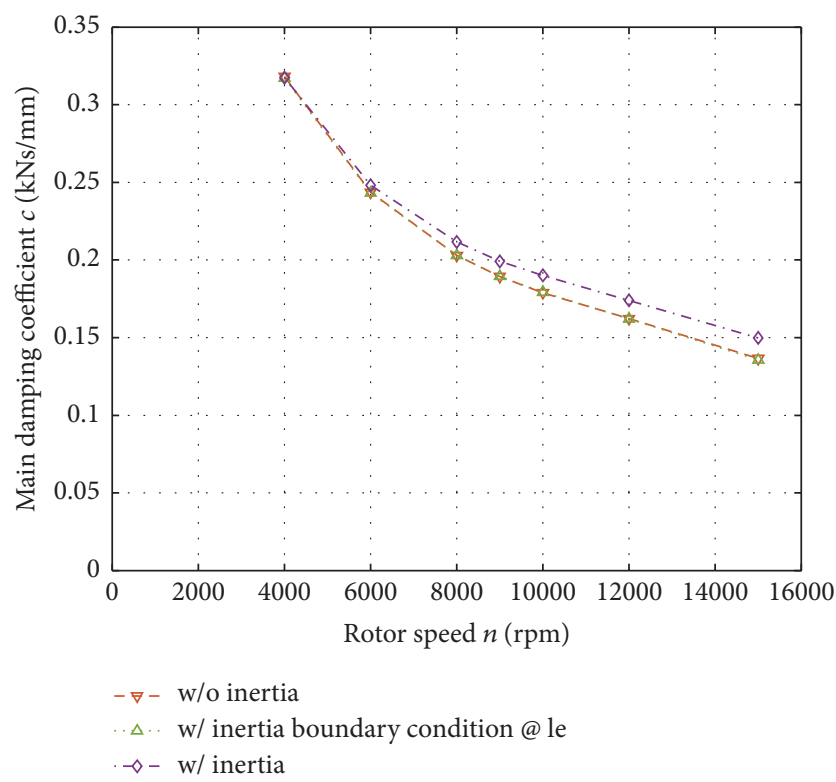

FIGURE 18: Comparison of predicted synchronous main bearing damping for different simulation boundary conditions (TPB120, $p_{q}=2.0 \mathrm{MPa}, Q=90 \mathrm{l} / \mathrm{min}, T_{\text {sup }}=50^{\circ} \mathrm{C}, z=36 \mathrm{~mm}$, and $\left.k_{\text {pivot }}=0.8 \mathrm{kN} / \mathrm{mm}\right)$.

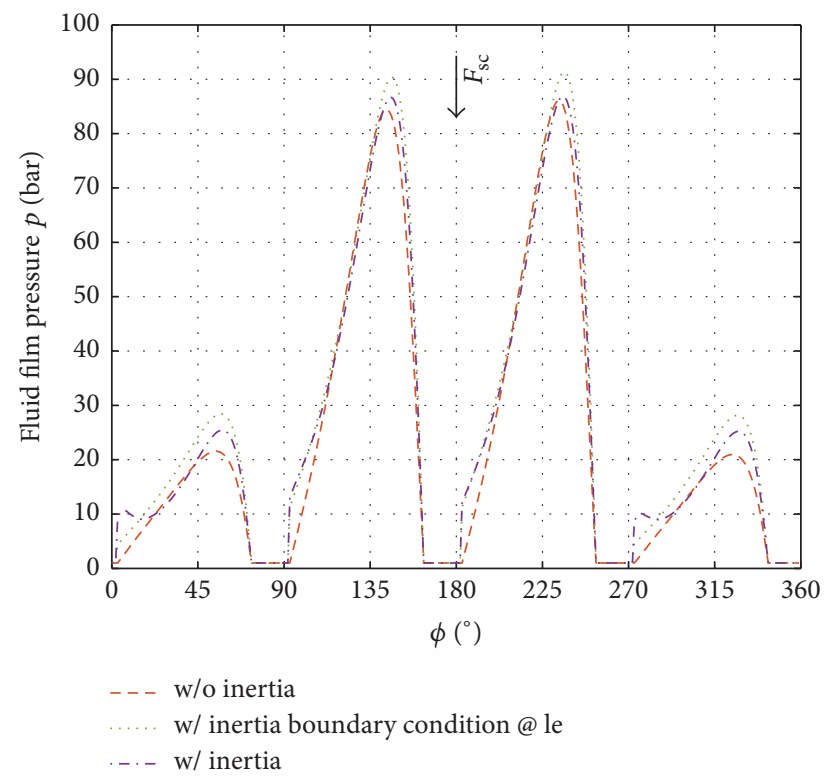

FIGURE 19: Comparison of local pressure predicted for different simulation boundary conditions (TPB120, $p_{q}=2.0 \mathrm{MPa}, Q=$ $90 \mathrm{l} / \mathrm{min}, T_{\text {sup }}=50^{\circ} \mathrm{C}$, and $z=36 \mathrm{~mm}$ ).

distribution. The available measurement data depicted in Figure 9 and Figures 11-14 includes high uncertainties in quantifying the actual pressure characteristic at leading edge. These analytical steps would provide the ability to improve modelling and to judge about special questions of implementation since predictions indicate a nonnegligible influence on characteristic parameters of bearing operation.

\section{Nomenclature}

Symbols

\begin{tabular}{|c|c|}
\hline$B:$ & Axial bearing length \\
\hline$C_{R}:$ & Bearing radial clearance, $C_{R}=R-r$ \\
\hline$c_{p}:$ & Lubricant specific heat \\
\hline$D:$ & Bearing diameter \\
\hline$F:$ & Bearing force \\
\hline$h:$ & Film thickness \\
\hline$H:$ & $\begin{array}{l}\text { Relative lubricant film thickness, } \\
H=h / C_{R}\end{array}$ \\
\hline$I_{x x}, I_{x z}, I_{z z}:$ & Integrals of inertia forces \\
\hline$K_{x}, K_{z}:$ & Turbulence factors \\
\hline$m:$ & Pad preload \\
\hline$n:$ & Rotational speed \\
\hline$p:$ & Pressure \\
\hline$p_{q}:$ & Specific bearing load, $p_{q}=F /(B D)$ \\
\hline Q: & Lubricant flow rate \\
\hline$R:$ & Journal bearing inside radius \\
\hline$R_{B}:$ & Pad bore radius \\
\hline$r:$ & Journal radius \\
\hline Re: & Reynolds number, $\operatorname{Re}=\rho \omega r C_{R} / \eta$ \\
\hline $\mathrm{Re}_{\delta}$ & $\begin{array}{l}\text { Reynolds number related to boundary } \\
\text { layer thickness, } \operatorname{Re}=\rho \omega r h_{\delta} / \eta\end{array}$ \\
\hline $\operatorname{Re}_{\mathrm{eff}}:$ & $\begin{array}{l}\text { Effective Reynolds number, } \\
\operatorname{Re}=\rho \omega r C_{R, \text { eff }} / \eta_{\text {eff }}\end{array}$ \\
\hline $\operatorname{Re}^{*}:$ & $\operatorname{Re}^{*}=\operatorname{Re} \cdot \psi$ \\
\hline$s:$ & Radial displacement \\
\hline$T:$ & Temperature \\
\hline$t_{B}:$ & Pad thickness \\
\hline$U:$ & Surface speed \\
\hline$u:$ & Flow velocities \\
\hline$x, y, z:$ & Cartesian coordinates \\
\hline$\alpha_{1}, \alpha_{2}, \alpha_{3}:$ & Inertia flow parameters \\
\hline$\beta:$ & Attitude angle of the journal \\
\hline$\delta:$ & Tilting angle, boundary layer thickness \\
\hline$\varepsilon:$ & Relative eccentricity of the journal \\
\hline$\eta:$ & Lubricant dynamic viscosity \\
\hline$\eta_{m}^{*}:$ & $\begin{array}{l}\text { Ratio of mean and related lubricant } \\
\text { dynamic viscosity }\end{array}$ \\
\hline$\Theta:$ & Local fill factor \\
\hline$v:$ & Lubricant kinematic viscosity \\
\hline$\rho:$ & Density \\
\hline$\varphi:$ & $\begin{array}{l}\text { Angular coordinate in circumferential } \\
\text { direction }\end{array}$ \\
\hline$\varphi_{F}:$ & Angular pivot position \\
\hline$\psi:$ & Relative bearing clearance. \\
\hline
\end{tabular}

Subscripts
bl: Boundary layer
cr: Critical
eff: Effective
le: Leading edge
sup: Supply. 


\section{Conflicts of Interest}

The authors declare that there are no conflicts of interest regarding the publication of this article.

\section{Acknowledgments}

The authors gratefully thank the German Federation of Industrial Research Associations (AiF e. V.) for the financial support of these investigations. The authors also thank the expert committees of the German Research Communities FVA e. V. and FVV e. V. for the technical and scientific steering of this research project.

\section{References}

[1] N. Mittwollen, Betriebsverhalten von Radialgleitlagern bei Hohen Umfangsgeschwindigkeiten und Hohen Thermischen Belastungen Theoretische Untersuchungen, vol. 187 of VDI Series 1, VDI-Verlag, Dusseldorf, Germany, 1990.

[2] C. M. Ettles, "Discussion: "Mixing inlet temperatures in hydrodynamic bearings" (Heshmat, H., and Pinkus, O., 1986, ASME J. Tribol., 108, pp. 231-244)," Journal of Tribology, vol. 108, no. 2, pp. 245-247, 1986.

[3] V. N. Constantinescu, S. Galetuse, and F. Kennedy, "On the comparison between lubrication theory, including turbulence and inertia forces, and some existing experimental data," Journal of Lubrication Technology, vol. 97, no. 3, pp. 439-449, 1975.

[4] T. Hagemann, Ölzuführungseinfluss bei schnell laufenden und hoch belasteten radialgleitlagern unter berücksichtigung des lagerdeformationsverhaltens [Ph.D. Thesis], TU Clausthal, Germany, 2011.

[5] T. Hagemann, S. Kukla, and H. Schwarze, "Measurement and prediction of the static operating conditions of a large turbine tilting-pad bearing under high circumferential speeds and heavy loads," in Proceedings of the ASME Turbo Expo 2013: Turbine Technical Conference and Exposition, GT2013-95004, American Society of Mechanical Engineers, San Antonio, Tex, USA, June 2013.

[6] T. Hagemann, S. Kukla, and H. Schwarze, "Measurement and prediction of the dynamic operating conditions of a large turbine tilting-pad bearing under high circumferential speeds and heavy loads," in Proceedings of the ASME Turbo Expo 2013: Turbine Technical Conference and Exposition, GT2013-95074, American Society of Mechanical Engineers, San Antonio, Tex, USA, June 2013.

[7] D. Dowson, "A generalized Reynolds equation for fluid-film lubrication," International Journal of Mechanical Sciences, vol. 4, no. 2, pp. 159-170, 1962.

[8] V. N. Constantinescu and S. Galetuse, "Operating characteristics of journal bearings in turbulent inertial flow," Journal of Lubrication Technology, vol. 104, no. 2, pp. 173-179, 1982.

[9] H. G. Elrod, "A cavitation algorithm," Journal of Lubrication Technology, vol. 103, no. 3, pp. 350-354, 1981.

[10] H. Schlichting and E. Gersten, Boundary Layer Theory, Springer-Verlag, Berlin, Germany, 10th edition, 2006.

[11] P. Pfeiffer, H. Blumenthal, and H. Schwarze, "HochleistungsGleitlagerprüfstand zur Ermittlung von tribologischen Kenngrößen hydrodynamischer Gleitlager für Turbomaschinenanwendungen," Tribologie und Schmierungstechnik, vol. 3, no. 62, p. 31ff, 2015.
[12] T. Hagemann, P. Pfeiffer, X. Si, C. Zeh, and H. Schwarze, Einfluss der Ölzuführung auf die Hydraulischen, Energetischen und Mechanischen Vorgänge in Schnell Laufenden und Hoch Belasteten Radialkippsegmentlagern, 1184, Forschungsvereinigung Antriebstechnik e.V., Frankfurt am Main, Germany, 2016.

[13] T. Hagemann, H. Blumenthal, C. Kraft, and H. Schwarze, "A study on energetic and hydraulic interaction of combined journal and thrust bearings," in Proceedings of the ASME Turbo Expo 2015: Turbine Technical Conference and Exposition, p. V07AT31A019, Montreal, Quebec, Canada, 2015.

[14] C. H. T. Pan, "Calculation of pressure, shear, and flow in lubricating films for high speed bearings," Journal of Lubrication Technology, vol. 96, no. 1, pp. 80-94, 1974.

[15] V. N. Constantinescu, "Special problems concerning lubrication phenomenas at large Reynolds numbers," in Proceedings of the 2nd Leeds-Lyon Symposium of Tribology, pp. 77-84, 1975.

[16] G. Hopf and D. Schüler, "Investigations on large turbine bearings working under transitional conditions between laminar and turbulent flow," Journal of Tribology, vol. 111, no. 4, pp. 628634, 1989. 


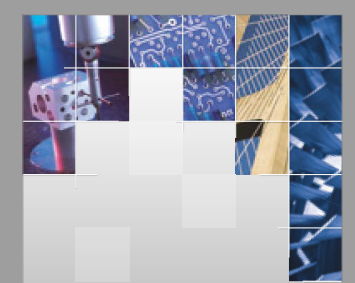

\section{Enfincering}
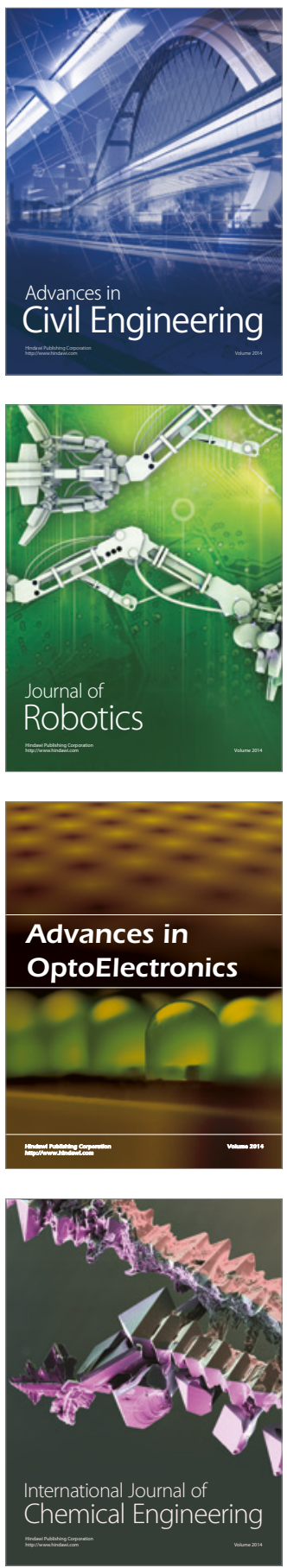

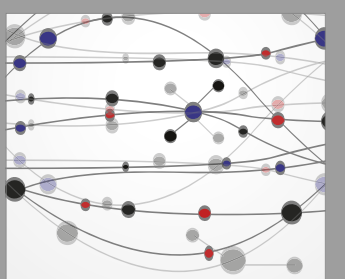

The Scientific World Journal

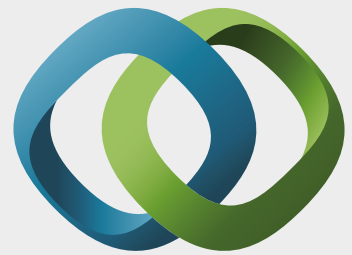

\section{Hindawi}

Submit your manuscripts at

https://www.hindawi.com
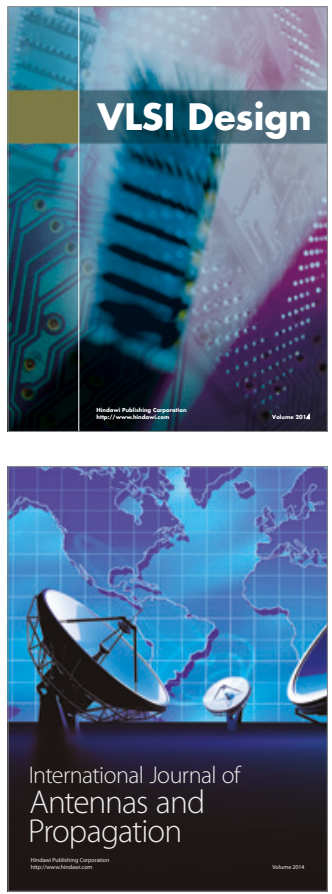

\section{Rotating}

Machinery
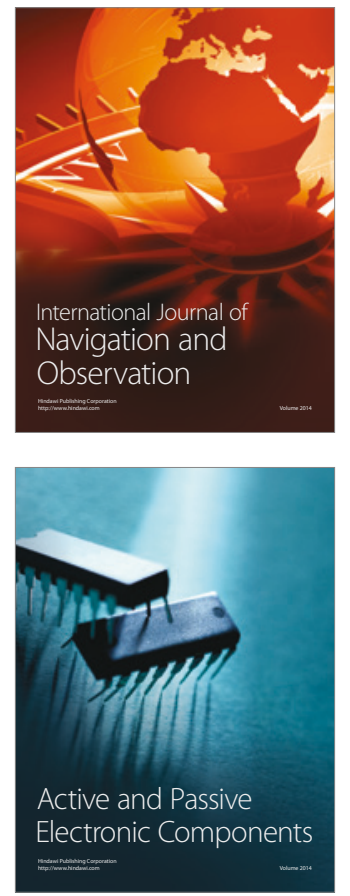
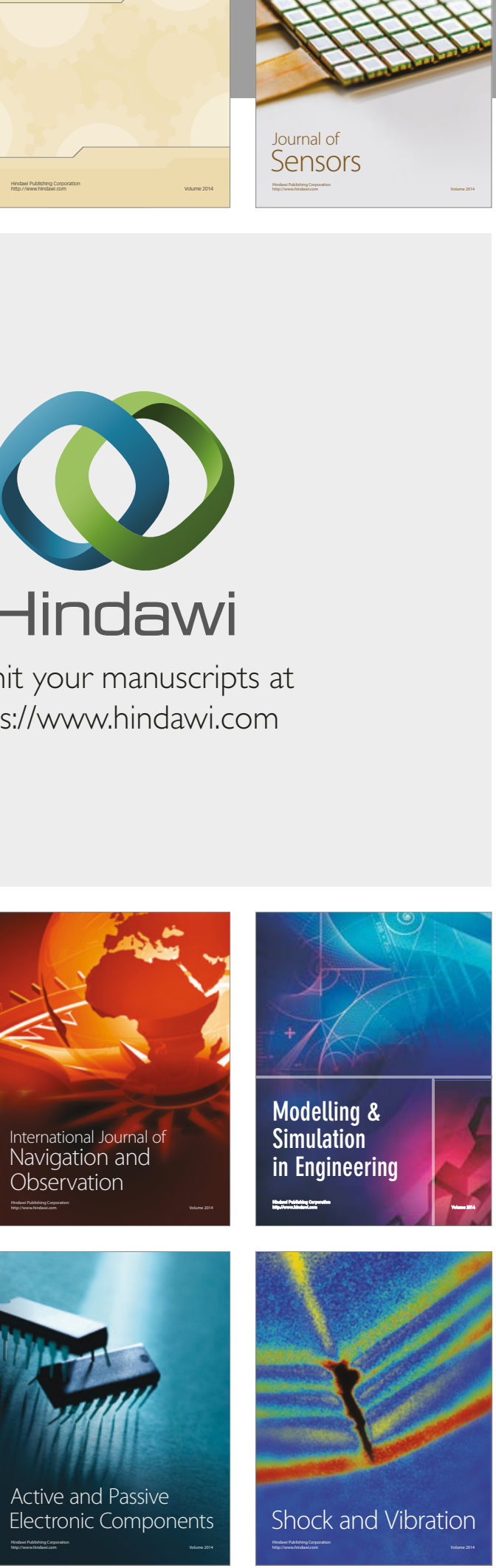
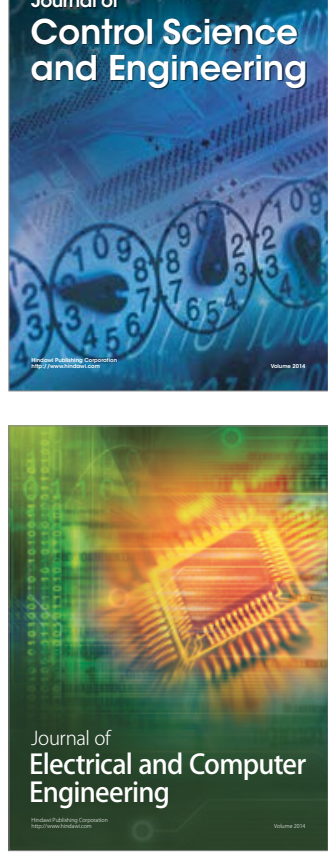

Distributed

Journal of

Control Science

and Engineering
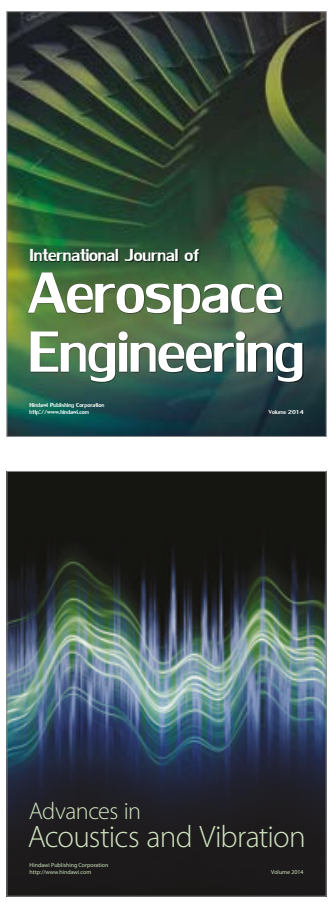

Sensor Networks 